\title{
Saphenofemoral vein crossover bypass grafting in iliofemoral vein obstruction
}

\author{
GLENN E. HAAS, DO
}

\section{Iliofemoral vein obstruction}

that causes venous hypertension in an extremity may produce symptoms that severely limit a patient's activities. A saphenofemoral venous crossover graft may relieve those symptoms. The procedure also is indicated for the repair of the venous system following severe, limbthreatening vascular trauma. For chronic obstruction, the procedure should be delayed for six months to allow for the possible development of adequate collateral circulation.

Iliofemoral vein obstruction may result in venous hypertension, with symptoms of claudication, eventual soft-tissue changes, and limb loss. Chronic obstruction may be secondary to thrombosis, pelvic tumor overgrowth, radiation therapy, or extensive adhesions. ${ }^{1-3}$ Severe injury that jeopardizes venous return in the lower extremity may occur in both the military and civilian settings.

Construction of a saphenofemoral venous crossover bypass graft provides a solution to this clinical problem. The procedure requires a minimal amount of soft-tissue dissection and may be performed using local or regional anesthesia. In this paper, three cases in which this technique was used successfully are reported, and indications for and the timing of surgery are discussed.

\section{Report of cases}

\section{Case 1}

A 56-year-old woman had had several episodes of deepvein thrombophlebitis and superficial phlebitis of the left leg. These findings had been documented via ascending phlebography. Prior to these episodes, she had undergone abdominal hysterectomy. At a later date, she had had the greater saphenous vein on the left side removed.

The leg continued to be swollen and tender. There were no skin changes or ulcerations. Phlebography demonstrated occlusion of the left iliac vein (Fig 1). The vena cava was shown to be patent.
The patient underwent venous crossover grafting. The right-sided greater saphenous vein was harvested in the normal fashion, but it was not disconnected from the right common femoral vein. Instead, it was passed through a suprapubic tunnel and anastomosed to the common femoral vein on the left.

Postoperatively, the swelling resolved. The patient's maintenance regimen included sodium warfarin therapy and compression stockings. Twice she has developed episodes of superficial phlebitis, but the crossover graft remains patent 17 months after surgery (Figs 2,3). There is no discrepancy in the size of either leg.

\section{Case 2}

In a motorcycle accident, a 21-year-old man sustained a crush injury to the left side of the groin and the pelvis. The pelvis was fractured in three sites, and there was an open wound in the groin. The right elbow also was fractured.

MAST trousers were in place when the patient was brought to the emergency room. His blood pressure was $80 / 60 \mathrm{~mm} \mathrm{Hg}$, and he was transported to the operating room for further evaluation and treatment.

The MAST trousers were removed. There was no femoral pulse on the left, and the left leg was ischemic. The

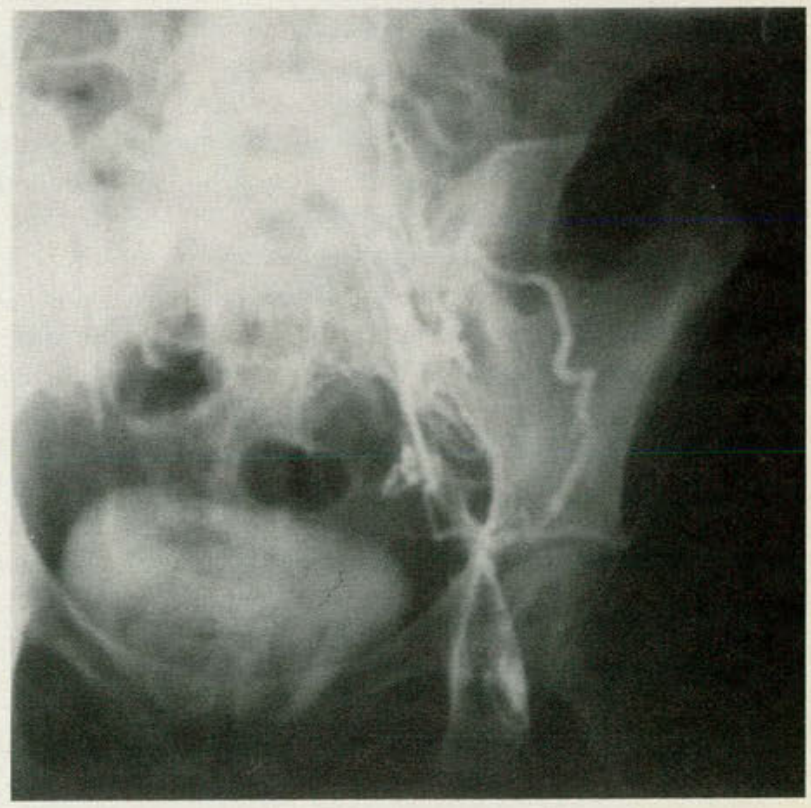

Fig 1. Iliac vein occlusion of left leg (case 1). 


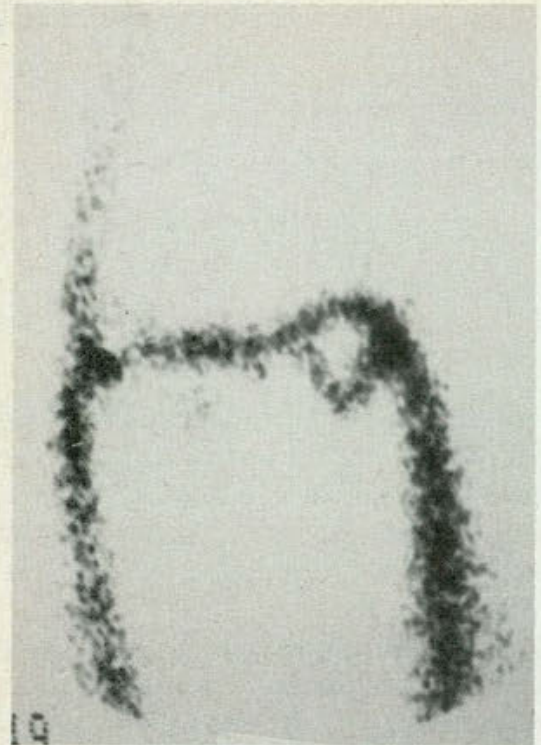

Fig 2. Patent venous crossover graft seen on isotope venogram (case 1).

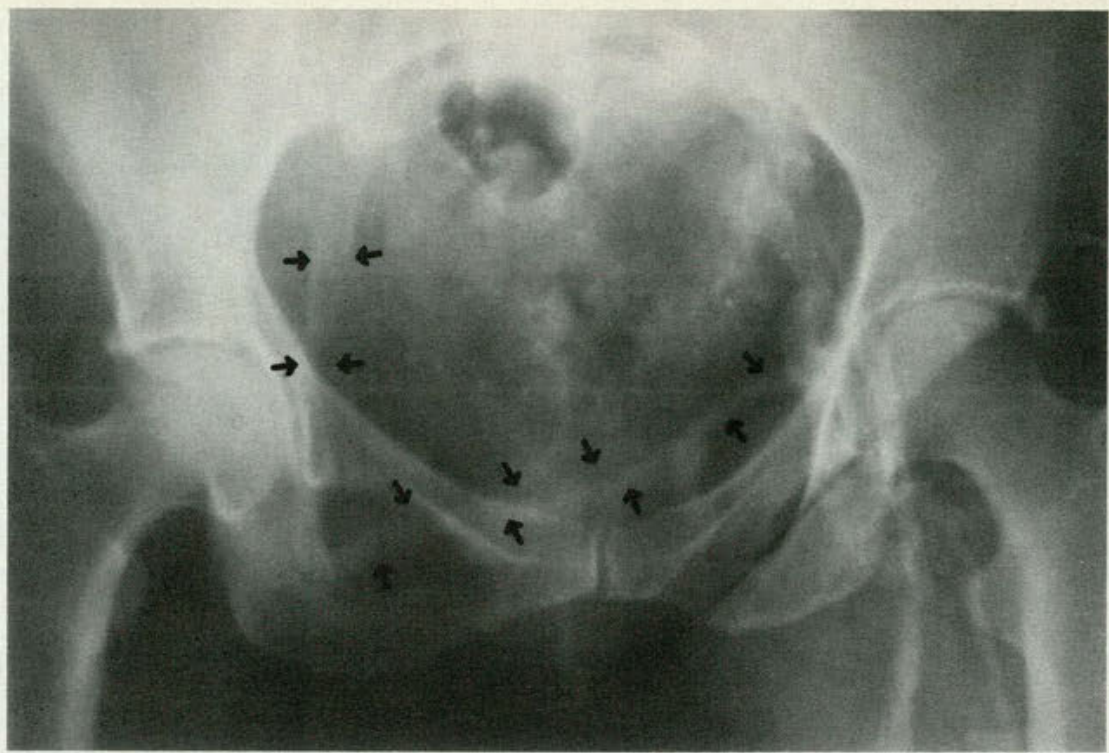

Fig 3. Phlebogram demonstrates patent venous crossover graft (case 1). hemorrhaging wound in the groin was packed, and the patient was intubated for general anesthesia.

Angiography demonstrated complete occlusion of the left external iliac artery (Fig 4). Surgical exploration of the left leg disclosed complete laceration of the greater saphenous and superficial femoral veins. The superficial femoral artery was crushed and thrombosed; the femoral nerve appeared to be intact. There was extensive muscle and soft tissue damage. The pudendal canal was widely patent and hemorrhaging actively.

The left superficial femoral artery was repaired with a reverse vein interposition graft, in an end-to-end fashion. The greater saphenous vein on the right was harvested but allowed to remain attached to the right common femoral vein. It was passed through a superficial suprapubic tunnel and anastomosed to the left superficial femoral vein. There was adequate flow through the crossover graft. The transected ends of the crushed greater saphenous vein were ligated. The pelvic fractures were reduced with an external fixation device (Fig 5). The open wound in the groin was packed to control blood loss. Fasciotomy of the anterior and posterior compartments on the left side was performed. The right elbow fracture was reduced with pins and plaster.

Postoperatively, a ventilator was required for 72 hours, and the patient's left leg was elevated. There was a mild degree of swelling in the leg. The pelvic bleeding subsided. A considerable portion of skin in the injured area sloughed off, and multiple skin grafts were needed. The vascular bypasses remained patent, and the skin healed well.

The pelvic fixation device was removed 14 weeks after surgery. At that time, the left ankle/brachial index was $115 \%$ and equal to that on the right side. Phlebography demonstrated a patent deep venous system and cross-

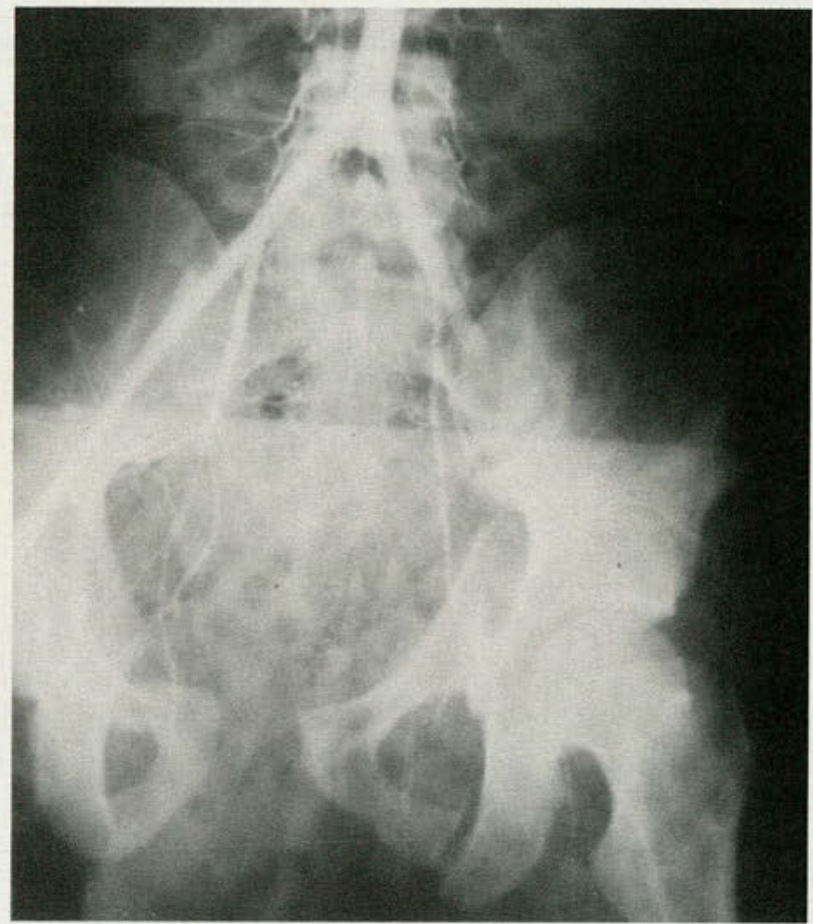

Fig 4. Occlusion of the left common iliac artery and associated pelvic fractures (case 2).

over graft (Figs 6,7). The patient returned to a sedentary occupation five months after surgery.

\section{Case 3}

A 40-year-old woman had experienced multiple episodes of superficial thrombophlebitis in her left leg. She un- 
The \#1 prescribed allergy
in the U.S. and worldwide The \#1 prescribed allergy
in the U.S. and worldwide NO ANTIHISTAMINE OLD OR NEW IS MORE EFFECTIVE

Maximum efficacy - proven in 30 double-blind clinical studies ${ }^{1-5}$

Fast onset of action-most patients experience significant relief within 1 hour, ${ }^{6+}$ maximum efficacy in 3-4 hours ${ }^{7 *}$

Efficacy maintained with through-the-season use $\mathrm{s}^{8-10}$

Unmatched patient preference $-77 \%$ of patients who started on Seldane and obtained another prescription in the category refilled that prescription with Seldane.

(Based upon a 1986 nationwide study of 640 patient members of prepaid group benefit plans.)

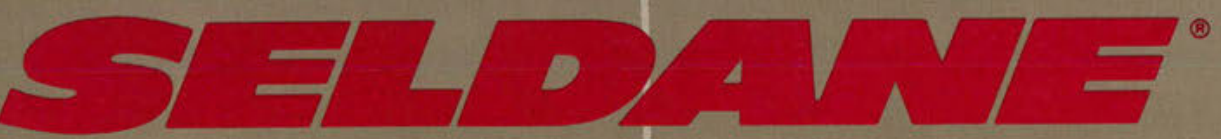

(terfenadine) 60 mg tablets BID

for seasonal allergic rhinitis

\section{The ideal profile for fast, on-the-job relief}

* Based upon worldwide prescription and distribution information (1986-1988)-data on file.

+ In most hay fever patients $(55 \%)$.

** In studies utilizing the histamine-induced skin wheal test. 


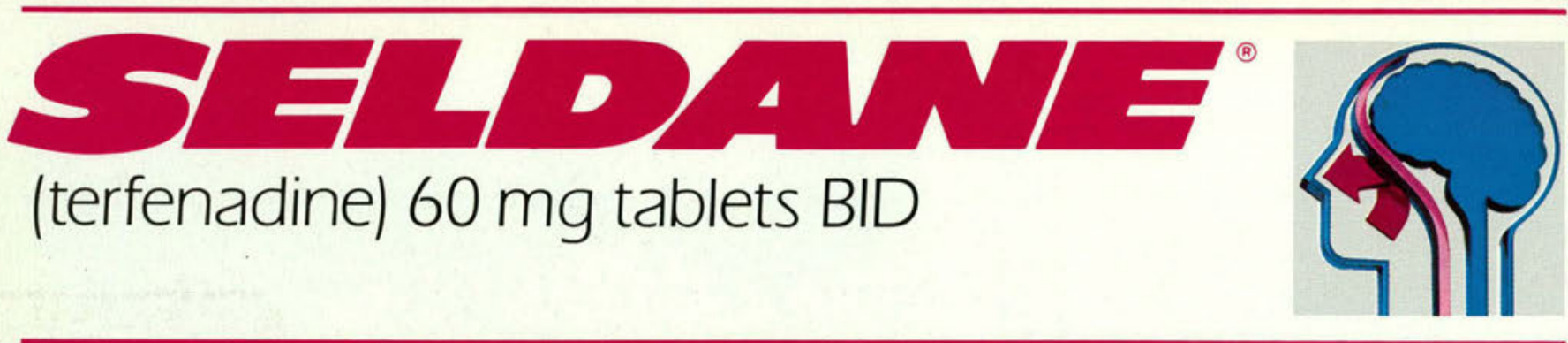

\section{- Fast, unsurpassed relief}

- Efficacy maintained in through-the-season use

- B.i.d. dosing for high patient compliance

- High patient preference

\section{- Lets patients stay alert so they can perform at their best}

\section{Seldane ${ }^{\circledR}$ (terfenadine) 60 mg Tablets \\ BRIEF SUMMARY \\ CAUTION: Federal law prohibits dispensing without prescription}

DESCRIPTION

Seldane (terfenadine) is available as tablets for oral administration. Each tablet contains $60 \mathrm{mg}$ terfenadine. Tablets also contain, as inactive ingredients: corn starch, gelatin, lactose, magnesium stearate, and sodium bicarbonate.

INDICATIONS AND USAGE

Seldane is indicated for the relief of symptoms associated with seasonal allergic rhinitis such as sneezing, rhinorrhea, pruritus, and lacrimation.

CONTRAINDICATIONS

Seldane is contraindicated in patients with a known hypersensitivity to terfenadine or any of its ingredients.

\section{PRECAUTIONS}

Information for patients

Patients taking Seldane should receive the following information and instructions. Antihistamines are prescribed to reduce allergic symptoms. Patients should be questioned about pregnancy or lactation potential benefit justifies the potential risk to fetus or baby. Patients should be instructed to take Seldane only as needed and not to exceed the prescribed dose. Patients should also be instructed to store this medication in a tightly closed container in a cool, dry place, away from heat or direct sunlight, and away from children.

Carcinogenesis, mutagenesis, impairment of fertility

Oral doses of terfenadine corresponding to 63 times the recommended human daily dose, in mice for 18 months or in rats for 24 months, revealed no evidence of tumorigenicity. Microbial and micronucleus test assays with terfenadine have revealed no evidence of mutagenesis.

Reproduction and fertility studies in rats showed no effects on male or female fertility at oral doses of up to 21 times the human daily dose. At 63 times the human daily dose there was a small but significant reduction in implants and at 125 times the human daily dose reduced implants and increased

Pregnancy Category C

There was no evidence of animal teratogenicity. Reproduction studies have been performed in rats at There was no evidence of animal teratogenicity. Reproduction studies have been performed in rats at doses 63 times and 125 times the human daily dose and have revealed decreased pup weight gain and survival when terfenadine was administered throughout pregnancy and lactation. There are no adequate and well-controlled studies in pregnant women. Seld

potential benefit justifies Neldane is not recommended for nursing women. The drug has caused decreased pup weight gain and survival in rats given doses 63 times and 125 times the human daily dose throughout pregnancy and lactation. Effects on pups exposed to Seldane only during lactation are not known, and there are no
adequate and well-controlled studies in women during lactation. Safety and effectiveness of Seldane in children below the age of 12 years have not been established.

Consideration should be given to potential anticholinergic (drying) effects in patients with lower airway disease, including asthma.

ADVERSE REACTIONS

Experience from clinical studies, including both controlled and uncontrolled studies involving more than 2,400 patients who received Seldane, provides information on adverse experience incidence for periods of a few days up to six months. The usual dose in these studies was $60 \mathrm{mg}$ twice daily, but in a small number of patients, the dose was as low as $20 \mathrm{mg}$ twice a day, or as high as $600 \mathrm{mg}$ daily.

In controlled clinical studies using the recommended dose of $60 \mathrm{mg}$ b.i.d., the incidence of reported adverse effects in patients receiving Seldane was similar to that reported in patients receiving placebo (See Table below.)

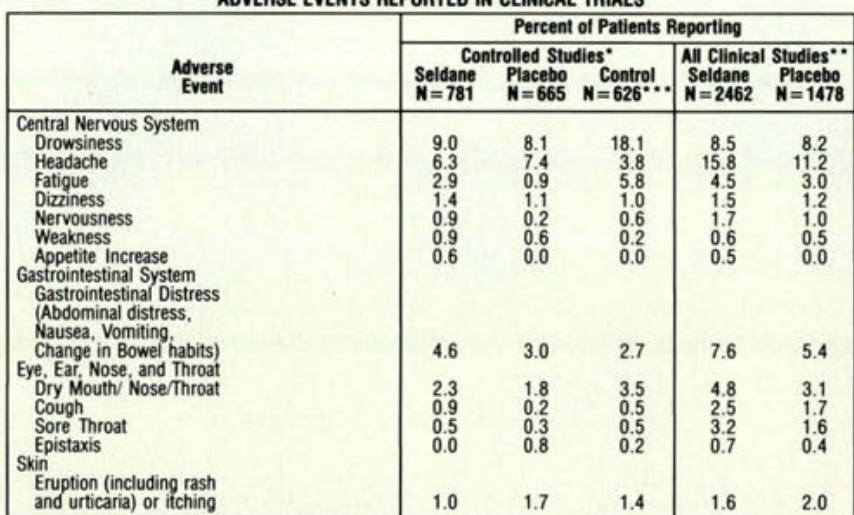

"Duration of treatment in "CONTROLLED STUDIES" was usually 7-14 DAYS

..Duration of treatment in "ALL CLINICAL STUDIES" was up to 6 months

CONTROL DRUGS: Chlorpheniramine (291 patients), d-Chlorpheniramine (189 patients), Clemastine (146

In addition to the more frequent side effects reported in clinical trials (See Table), adverse effects have been reported at a lower incidence in clinical trials and/or spontaneously during marketing of Seldane that warrant listing as possibly associated with drug administration. These include: alopecia, (hair loss or thinning), anaphylaxis, angioedema, arrhythmia (including ventricular tachyarrhythmia), bronchospasm, confusion, depression, galactorrmea, hypotension, insomnia, menstrual disorders (includin dysmenorrinea), musculoskeletal symptoms, nightmares, palpitation, paresthesia, photosensitivity, prolonged QT interval, seizures, sweating, syncope, tachycardia, tremor, urinary frequency, and visua disturbances. In clinical trials, several instances of mild, or in one case, moderate transaminase elevations were seen in patients receiving Seldane. Mild elevations were also seen in placebo treated patients. Marketing experiences include isolated reports of jaundice, cholestatic hepatitis, and hepatitis: in most cases available information is incomplete. In neither the clinical trials nor marketing experience is a causal relationship of liver abnormalities to Seldane use clear.

OVERDOSAGE

Information concerning possible overdosage and its treatment appears in Full Prescribing Information DOSAGE AND ADMINISTRATION

The usual dosage for adults and children 12 years and older is $60 \mathrm{mg}$ (1 tablet) twice daily. Product Information as of June, 1988

MERRELL DOW PHARMACEUTICALS INC.

Subsidiary of The Dow Chemical Company

Chio 45215, U.S.A.

Merrell Dow

PRINTED IN U.S.A.

References: 1. Kemp JP, Buckley CE, Gershwin ME, et al: Multicenter, double-blind, placebo-controlled trial of terfenadine in seasonal allergic rhinitis and conjunctivitis. Ann Allergy 1985:54:502-509. 2. Backhouse CI, Brewster BS, Lockhart JDF, et al: Terfenadine in allergic rhinitis. A comparative trial of a new antihistamine versus chlorpheniramine and placebo. Practitioner 1982:226:347-348, 351. 3. Buckley CE, Buchman E, Falliers CJ, et al: Terfenadine treatment of fall hay fever. Ann Allergy 1988:60:123-128. 4. Melillo G. D'Amato G, Zanussi C, et al: A multicentre controlled trial of terfenadine, dexchlorpheniramine, and placebo in allergic rhinitis. Arzneim-Forsch/Drug Res 1982:32:1202-1203. 5. Data on file, MERRELL DOW PHARMACEUTICALS INC., Cincinnati, Ohio 45215. 6. Murphy-

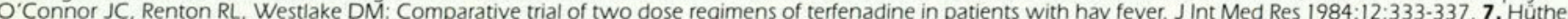

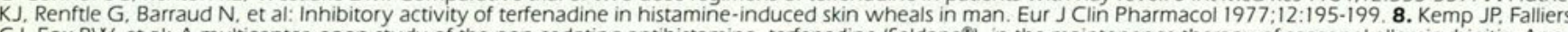

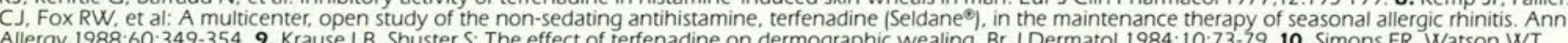
Allergy 1988;60:349-354. 9. Krause LB, Shuster S: The effect of terfenadine on dermographic wealing. Br J Dermatol 1984:10:73-79. 10. Simons FR, Watson WT, Simons KJ: Lack of subsensitivity to terfenadine during long-term treatment. J Allergy Clin Immunol 1988:82:1068-1075. 


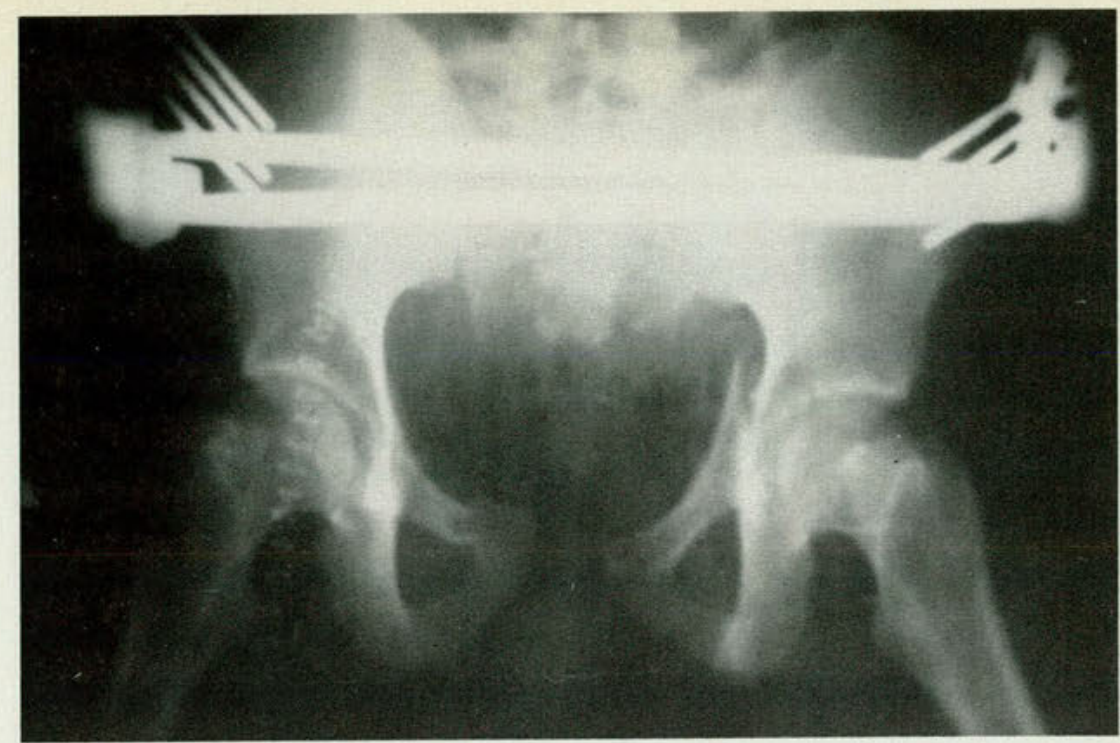

Fig 5. External fixation device, which was applied after the vascular reconstructions, stabilized the pelvic fractures and helped control hemorrhaging (case 2). derwent ligation, division, and stripping of the leftsided greater saphenous vein two months before undergoing hysterectomy. Both surgical procedures were done without complication.

Three weeks after the hysterectomy, she developed severe pain and swelling in the left leg. Retrograde phlebography confirmed complete occlusion of the left common iliac vein (Fig 8). There appeared to be an external component to the obstruction.

The patient received sodium warfarin for seven months. However, the swelling persisted, and the sensation of heaviness in the leg was unrelieved. Stasis dermatitis on the left medial ankle region appeared to become more intense and pruritic.

Venography demonstrated a failure to develop adequate collateral venous channels, and the patient underwent saphenofemoral vein bypass. The greater saphenous vein on the right was harvested in the normal fashion, but it was allowed to remain attached to the right common femoral vein.

The postoperative course was uncomplicated. The swelling subsided and the discomfort abated. A maintenance regimen of sodium warfarin and compression stockings was prescribed. Radioactive isotope venography performed four months after surgery demonstrated a patent crossover graft (Fig 9).

\section{Discussion}

Palma ${ }^{4}$ first described the saphenofemoral crossover venous bypass graft in 1960 . Through the continuing investigations, observations, and refinements of Bergan and associates, ${ }^{5}$ Dale, ${ }^{1,6,7}$ and Husni, ${ }^{8,9}$ nearly a $75 \%$ rate of success or improvement in symptoms can be expected following this procedure. $^{5}$

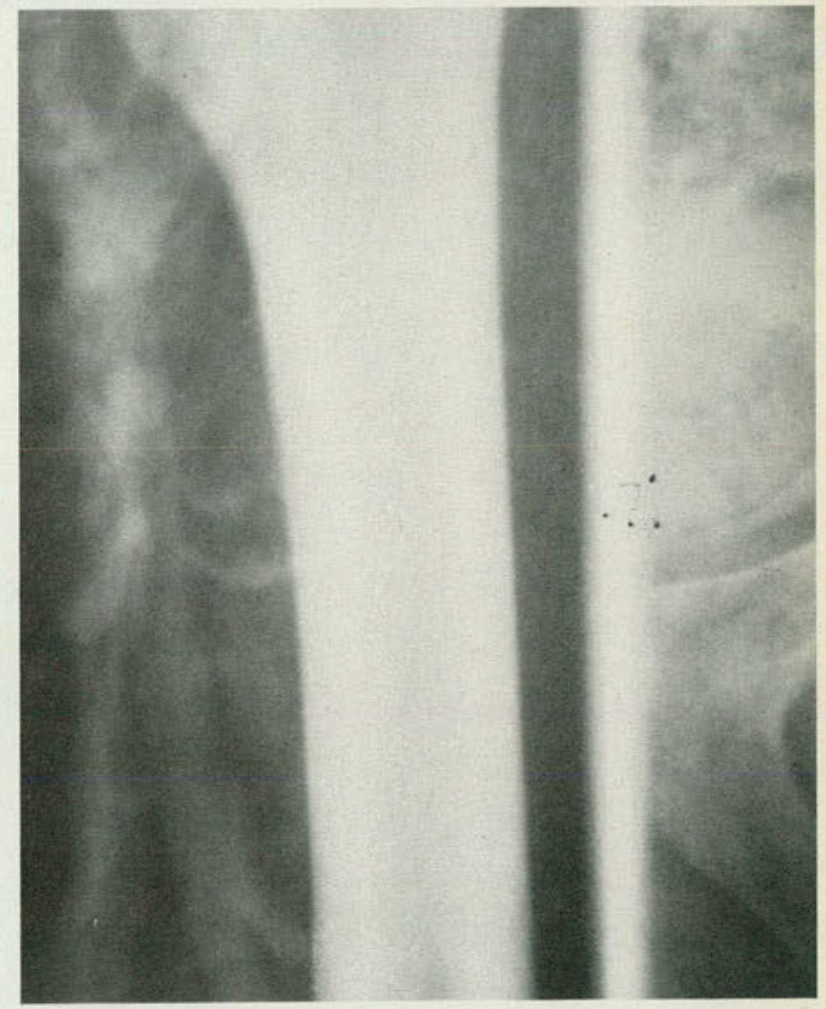

Fig 6. Patent deep venous system 14 weeks after surgery (case 2).

For whom is the operation indicated? Venous hypertension in a lower extremity secondary to iliac vein thrombosis most likely is due to a failure to develop adequate venous collateral circulation and to recanalize the thrombosis. Varicose veins and 
Fig 7. Patent venous crossover graft 14 weeks after surgery (case 2).

Fig 8. Complete occlusion of the left iliac vein (case 3 ).
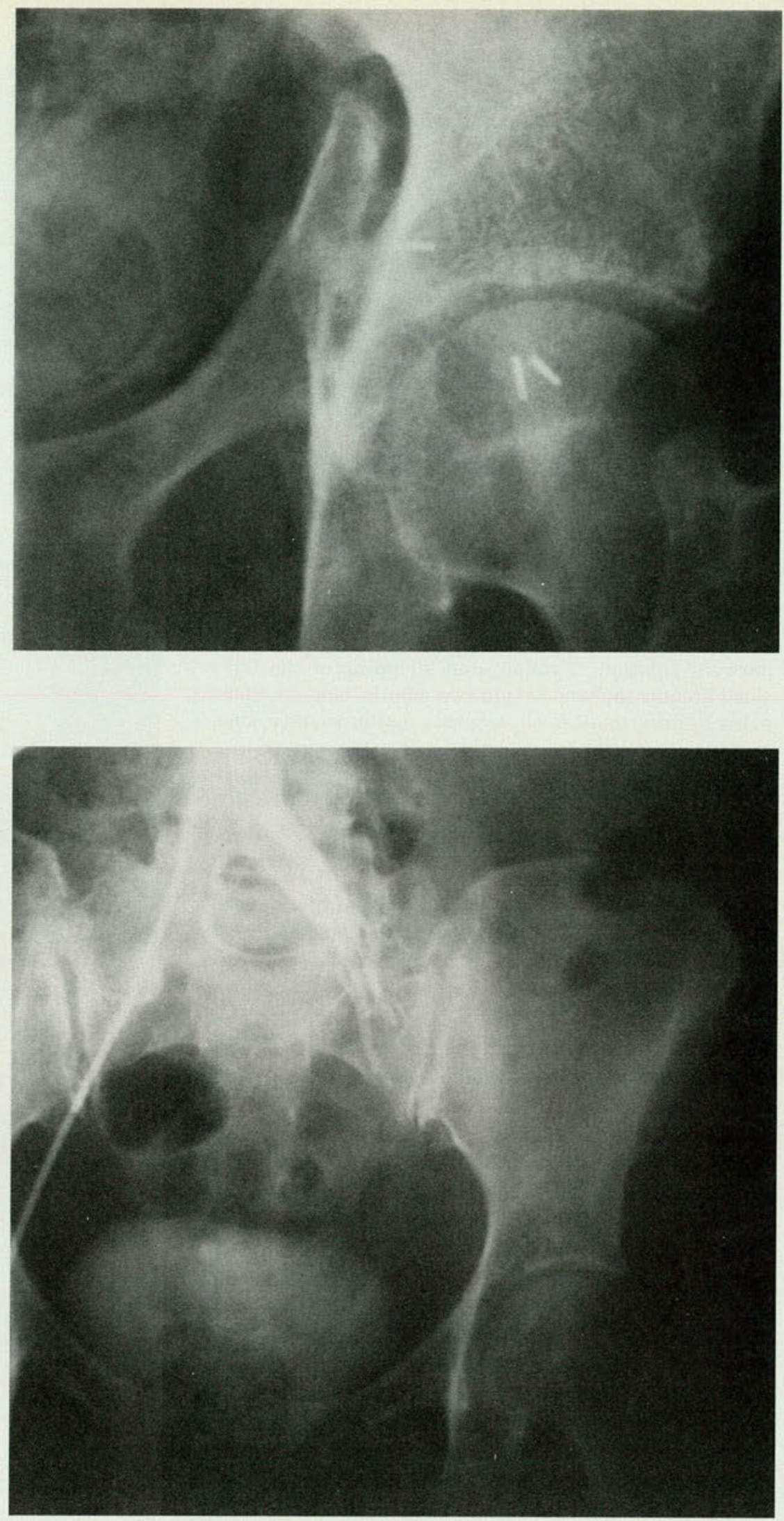
diseased perforating veins are best treated with local ligation and division.

When ulceration develops, a bypass graft alone may not be sufficient to heal the ulcer. However the crossover graft is a fine adjunct to local venous surgery. $5,10,11$ The contralateral greater saphenous vein should be free of disease. Patients with extraluminal venous obstruction do quite well with this procedure 6,8

Crossover grafting should be performed when there is no evidence of active phlebitis. For patients with iliac vein thrombosis, the procedure should be delayed no less than six months, which will allow for possible recanalization of thrombi and the development of collateral venous channels. Preoperative phlebography is required to confirm the diagnosis, to ensure that the inferior vena cava is patent, and to investigate the distal venous system in the affected limb.

The decreased flow velocity in the venous system is of mild concern. Autogenous vein grafts appear to produce the best results. The crossover graft requires only one anastomosis, but free interposition vein grafts also produce adequate results. ${ }^{9}$

Synthetic venous bypass grafts uniformly have been unsuccessful. ${ }^{7,12-14}$ Long-term survival of either Dacron or expanded polytetrafluoroethylene (PTFE) is limited, ${ }^{12}$ even when it is supplemented by an arteriovenous fistula. Dale and $\operatorname{Scott}^{7}$ strongly emphasize the importance of the size of the anastomosis and delicate surgical technique.

A major advantage of autogenous venous bypass grafting is its ability to recanalize a thrombosis. This process is similar to the recanalization process that occurs in native veins that develop thromboses. Why thrombi do not recanalize in either arterial bypass grafts or prosthetic venous bypass grafts remains unknown. Reasons such as altered ion exchange or diminished oxygen diffusion have been proposed but not proved. ${ }^{17}$ The introduction of externally supported PTFE grafts may lengthen the survival of the prosthetic graft.

Dale and $\operatorname{Scott}^{7}$ initially stressed the importance of the vein's internal pressure and blood flow. Commonly, the patients receive an anticoagulant (heparin or sodium warfarin, or both) postoperatively. Construction of an arteriovenous fistula distal to the venous anastomosis has been recommended but not adopted routinely. The fistula generally is a temporary device to improve flow pressures and collateralization. ${ }^{14,15}$ Unfortunately, the fistula can not guarantee outstanding results and may cause considerable edema in the extremity. Consequently, this adjunctive procedure has not been adopted as an integral part of the venous bypass.

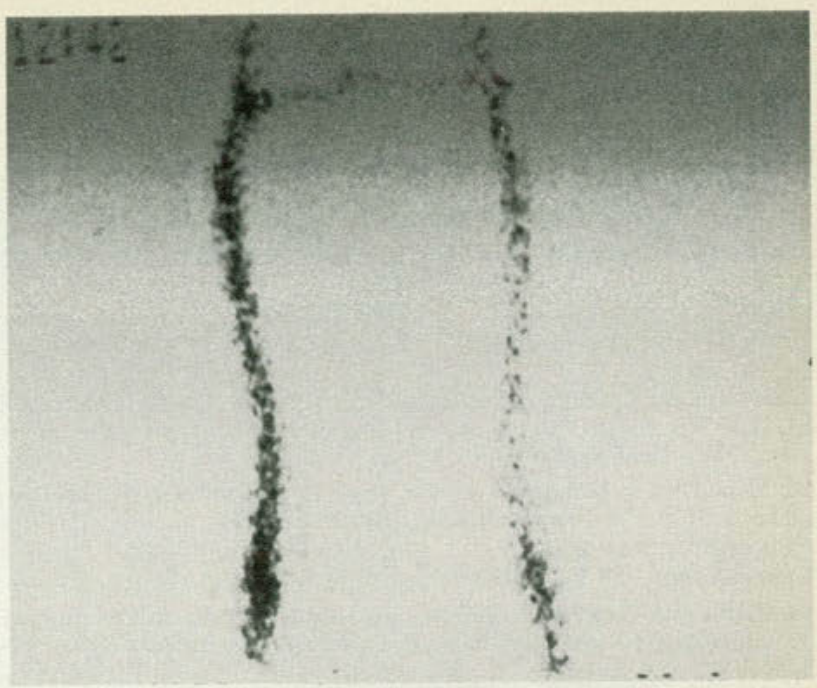

Fig 9. Patent venous crossover graft four months postoperatively (case 3).

Traumatic injury to the major veins of the lower extremities routinely require repair. ${ }^{16}$ Simple suturing frequently is all that is necessary. When the injury is extensive, the basic tenets of vessel repair (adequate debridement, reanastomosis without tension, removal of proximal and distal thrombi, and adequate soft-tissue coverage) are imperative. The contralateral saphenous vein should be made available for an interposition graft, a vein patch, or, as in case 2 , a crossover vein graft.

Isolated venous trauma has resulted in recuperative delays and limb loss. ${ }^{17}$ When associated with concomitant arterial injury, limb loss is common. ${ }^{18}$ Extensive and lengthy procedures that imperil the patient's chances for survival should be avoided. ${ }^{19}$ The extent of venous injury (both superficial femoral and greater saphenous veins) would seriously have jeopardized the chances for limb salvage. Construction of an arteriovenous fistula in a grossly contaminated area was not indicated.

\section{Conclusions}

Saphenofemoral crossover bypass grafting may be performed not only for chronic iliac vein obstruction but also for severe venous trauma of the lower extremity. In chronic obstruction, results are better for relief of venous claudication symptoms. Extensively diseased and thrombotic veins with associated ulcerations are not corrected readily with a crossover graft alone.

The incidence of limb loss associated with major venous trauma to a lower extremity should encourage an aggressive approach toward reconstruction of the venous system. Crossover grafting provides 
a surgical alternative in restoring venous continuity to a severely injured lower extremity.

Construction of a temporary arteriovenous fistula was not necessary in the three reported cases. Use of anticoagulants is recommended for chronic venous disease, but it may be contraindicated in major trauma cases.

1. Dale WA: Surgery for chronic peripheral venous hypertension. Contemp Surg 1980;16:28-43.

2. Matsubara J, Hirai M, Kawai S, et al: Treatment of iliofemoral venous occlusion. J Cardiovasc Surg 1982;23:256-260.

3. Ellis PR, Del Rosario VC: Left iliac vein 'adhesions.' Surgery 1968;63:166.

4. Palma EC, Esperon R: Vein transplants and grafts in the surgical treatment of the postphlebitis syndrome. J Cardiovasc Surg 1960;1:94107.

5. Bergan JJ, Yao JS, Flinn WR, et al: Surgical treatment of venous obstruction and insufficiency. $J$ Vasc Surg 1986;3:174-181.

6. Dale WA: Crossover vein grafts for relief of iliofeporal venous block. Surgery 1965;57:608-612.

7. Dale WA, Scott HW Jr: Grafts of the venous system. Surgery 1963;53:52-54.

8. Husni EA: Reconstruction of veins: The need for objectivity. J Cardiovasc Surg 1983;24:525-528.

9. Husni EA: In situ saphenopopliteal bypass graft for incompetence of the femoral and politeal veins. Surg Gynecol Obstet 1970;130:279-284.

10. Raju S: Venous insufficiency of the lower limb and stasis ulceration: Changing concepts and management. Ann Surg 1983;197:688-697.
11. Halliday P, Harris J, May J: Femoro-femoral crossover grafts (Palma operation): A long-term follow-up study, in Bergan JJ, Yao JS (eds) Surgery of the Veins. Orlando, Fla, Grune \& Stratton, Inc, 1984, pp 241 254.

12. Plate G, Einarsson E, Ekloff B, et al: Iliac vein obstruction associated with acute iliofemoral venous thrombosis: Results of early reconstruction using polytetrafluoroethylene grafts. Acta Chir Scand 1985; 151:607-611

13. Frileux C, Pillot-Bienayme P, Gillot C: Bypass of segmental obliterations of iliofemoral venous axis by transposition of saphenous vein $J$ Cardiovasc Surg 1972;13:409-414.

14. Ijima H, Kodama M, Hori M: Temporary arteriovenous fistula for venous reconstruction using synthetic graft: A clinical and experimental investigation. J Cardiovasc Surg 1985;26:131-136.

15. Edwards WS: A-V fistula after venous reconstruction: A simplified method of producing and obliterating the shunt. Ann Surg 1982;196:669671.

16. Rich NM, Hughes CW, Baugh JH: Management of venous injuries. Ann Surg 1970;171:724-730.

17. Rich NM, Hobson RW II, Wright CB, et al: Repair of lower extremity venous trauma: A more aggressive approach required. $J$ Trauma $1974 ; 14: 639-652$.

18. Rich NM, Jarstfer BS, Geer TM: Popliteal artery repair failure: Causes and possible prevention. J Cardiovasc Surg 1974;15:340-351.

19. Mullins RJ, Lucas CE, Ledgerwood AM: The natural history following venous ligation for civilian injuries. J Trauma 1980;20:737-743.

From the Department of Cardiothoracic Surgery, PresbyterianUniversity of Pennsylvania Medical Center, Philadelphia, 19104.

Reprint requests to Dr Haas, Suite 112, 400 Middletown Blvd, Langhorne, PA, 19047. 